\title{
Triplex Hybridization-Based Nanosystem for the Rapid Screening of Pneumocystis Pneumonia in Clinical Samples
}

\author{
Luis Pla 1,2,3, Anna Aviñó ${ }^{3,4}$, Ramón Eritja ${ }^{3,4}$ (®) Alba Ruiz-Gaitán ${ }^{5}$, Javier Pemán ${ }^{5}$, \\ Vicente Friaza ${ }^{6}$, Enrique J. Calderón 6,7 Dena Aznar 1,2,3,8,*(D), \\ Ramón Martínez-Máñez ${ }^{1,2,3,8, *(D)}$ and Sara Santiago-Felipe 1,2,3 \\ 1 Instituto Interuniversitario de Investigación de Reconocimiento Molecular y Desarrollo Tecnológico, \\ Universitat Politècnica de València, Universitat de València, Camino de Vera s/n, 46022 Valencia, Spain; \\ plablas@upv.es (L.P.); sasanfe@upvnet.upv.es (S.S.-F.) \\ 2 Unidad Mixta de Investigación en Nanomedicina y Sensores, Instituto de Investigación Sanitaria La Fe, \\ Universitat Politècnica de València, 46022 Valencia, Spain \\ 3 CIBER de Bioingeniería, Biomateriales y Nanomedicina (CIBER-BBN), Spain; aaagma@cid.csic.es (A.A.); \\ recgma@cid.csic.es (R.E.) \\ 4 Institute for Advanced Chemistry of Catalonia (IQAC), CSIC, Jordi Girona 18-26, 08034 Barcelona, Spain \\ 5 Grupo Acreditado de Infección Grave, Instituto de Investigación Sanitaria La Fe and Servicio de \\ Microbiología, Hospital Universitari i Politècnic La Fe, Avenida Fernando Abril Martorell, 46026 Valencia, \\ Spain; alba_ruiz@iislafe.es (A.R.-G.); peman_jav@gva.es (J.P.) \\ 6 Instituto de Biomedicina de Sevilla, Hospital Universitario Virgen del Rocío/Consejo Superior de \\ Investigaciones Científicas/Universidad de Sevilla, 41013 Sevilla, Spain; vfriaza-ibis@us.es (V.F.); \\ sandube@cica.es (E.J.C.) \\ 7 Centro de Investigación Biomédica en Red de Epidemiología y Salud Pública (CIBERESP), Spain \\ 8 Unidad Mixta UPV-CIPF de Investigación en Mecanismos de Enfermedades y Nanomedicina, \\ Universitat Politècnica de València, Centro de Investigación Príncipe Felipe, 46012 Valencia, Spain \\ * Correspondence: elazgi@upvnet.upv.es (E.A.); rmaez@qim.upv.es (R.M.-M.)
}

Received: 1 October 2020; Accepted: 13 November 2020; Published: 17 November 2020

\begin{abstract}
Pneumocystis pneumonia ( $\mathrm{PcP}$ ) is a disease produced by the opportunistic infection of the fungus Pneumocystis jirovecii. As delayed or unsuitable treatments increase the risk of mortality, the development of rapid and accurate diagnostic tools for PcP are of great importance. Unfortunately, current standard methods present severe limitations and are far from adequate. In this work, a time-competitive, sensitive and selective biosensor based on DNA-gated nanomaterials for the identification of $P$. jirovecii is presented. The biosensor consists of a nanoporous anodic alumina (NAA) scaffold which pores are filled with a dye reporter and capped with specific DNA oligonucleotides. In the presence of $P$. jirovecii genomic DNA, the gated biosensor is open, and the cargo is delivered to the solution where it is monitored through fluorescence spectroscopy. The use of capping oligonucleotides able to form duplex or triplex with $P$. jirovecii DNA is studied. The final diagnostic tool shows a limit of detection (LOD) of $1 \mathrm{nM}$ of target complementary DNA and does not require previous amplification steps. The method was applied to identify DNA from P. jirovecii in unmodified bronchoalveolar lavage, nasopharyngeal aspirates, and sputum samples in $60 \mathrm{~min}$. This is a promising alternative method for the routinely diagnosis of Pneumocystis pneumonia.
\end{abstract}

Keywords: nanoporous anodic alumina; Pneumocystis jirovecii; molecular gates; oligonucleotides; biosensor 


\section{Introduction}

Pneumocystis jirovecii is an opportunistic fungus that can cause asymptomatic or mild infection in healthy people and fulminating pneumonia in immunocompromised individuals [1]. Pneumocystis spp. can affect many species of mammals (rodent, horses, and primates) and presents strong specificity for host species. The fungus was identified as a human pathogen in the 1940s when it was detected in the lungs of children affected with interstitial pneumonia of plasmatic cells [2]. Usually, in humans, the pathogen is disseminated from person to person producing asymptomatic or subclinical infection; however, when it is transmitted to an immunocompromised host, a severe pneumonia can take place (Pneumocystis pneumonia, PcP) [3]. In the 1980s, the high incidence of acquired immunodeficiency syndrome (AIDS) lead to a markedly interest in PcP due to the high incidence in those patients. Nowadays, the widespread use of immunosuppressive treatments such as corticosteroid therapies, chemotherapies, or biological therapies, has increased the incidence of P. jirovecii infections. In addition, recent studies have provided evidence of transplacental transmission in humans and stablished a relation between $P$. jirovecii colonization in preterm infants and neonatal Respiratory Distress Syndrome risk $[4,5]$.

In the last decade, several published works have allowed a high progress in the knowledge of the Pneumocystis pathobiology; however, morbidity and mortality due to PcP still remains high, especially in developing countries. One of the main challenges in the diagnosis of $\mathrm{PcP}$ is the absence of a specific clinical manifestation, which difficult diagnosis and makes it stand on non-specific symptoms [6]. Therefore, a proper diagnosis of Pneumocystis pneumonia involves correct recognition of the fungus. Unfortunately, the current standard methods for P. jirovecii detection are far from adequate, and further aggravated by the impossibility to keep continuous fungus ex vivo axenic culture [7].

Classical methodologies for the identification of $P$. jirovecii comprise microscopic observation of stained biological samples that reveal the characteristic morphology of Pneumocystis cystic and/or trophic forms. These techniques provide sensitivity and specificity values between $60-75 \%$ and $80-90 \%$, respectively; however, they remain time-consuming and require high experienced staff and specific equipment [8-10]. Some alternatives for PCP diagnosis involve the detection of blood biomarkers that indicate the host-pathogen interaction, including (bio)molecules such as (1,3)- $\beta$-d-glucan (BG), lactate dehydrogenase (LDH), Krebs von den Lungen-6 antigen (KL-6), and adenosylmethionine (SAM) [10]. Nonetheless, despite their good sensitivity (70-95\%), the detected metabolites are not strictly specific to P. jirovecii infection, which significantly reduces the specificity values (50-70\%) [10]. On the other hand, serological methods detect the antibodies produced by the patient as consequence of the presence of the fungus, but despite their greater selectivity, they are expensive, require long-time procedures, and there is still a need to better characterize the immune response to obtain better standardized protocols $[9,11,12]$.

Among molecular techniques, PCR assays have revealed to be highly efficient, allowing even the early detection of the fungus in samples from patients that were confirmed negative by microscopic examination [8]. During the last 15 years, numerous PCR techniques for the detection of genomic DNA from P. jirovecii have been reported, obtaining sensitivity and specificity values close to $90-100 \%$. The most remarkable studies employ both conventional PCR and its variants nested-PCR, and real time PCR, and they are applied to recognize target gene such as the mitochondrial large subunit RNA (mtLSUrRNA), the internally transcribed spacer (ITS) or $18 \mathrm{~S}$ or $5 \mathrm{~S}$ ribosomal RNA (18S rRNA or 5S rRNA) [8]. However, despite its great potential, PCR is not exempt from limitations such us high susceptibility to polymerase inhibitors or cross contamination [13].

In the last decades, new diagnostic platforms based upon nanotechnology have become a reality thanks to their ability to provide sensitive, accurate and rapid results. For instance, nanotechnology has burst into Pneumocystis diagnosis by developing serological biosensors that uses gold nanoparticles (AuNPs) to detect anti-P. jirovecii antibodies by a colorimetric assay in a lateral flow immunoassay $[14,15]$. Nevertheless, the development of nanosensors for PcP detection is still an incipient area. However, this is a stimulating field of research and recent advances have demonstrated that the design of new hybrid 
organic-inorganic systems in a single entity can benefit from both, the potential of nanomaterials and the recognition, selectivity, and sensitivity properties of biomolecules. In that regard, several hybrid systems have been extensively applied in sensing and drug delivery applications [16-23].

Among the great variety of nanomaterials available, nanoporous anodic alumina (NAA) has been widely used because of its biocompatibility, high surface area, high loading capacity, and easy modification of the surface. Moreover, NAA supports can be easily prepared by cost-competitive and well-known production techniques [24]. NAA have additionally been used to develop capped stimuli-responsive systems, in which the mesoporous support is loaded with a cargo and capped with a biomolecule, so that only target molecules are able to induce cargo release. In NAA, oligonucleotides as capping systems have recently been demonstrated to be excellent candidates to detect and quantify a range of molecules and biomolecules [24,25]. Some of these tools rely on the use of DNA as caps and base their recognition mechanism on duplex hybridization interactions (DNA-DNA or DNA-RNA) between the probe and the target. Nevertheless, innovative triple-helix hybridization formats based on Hoogsteen and reverse-Hoogsteen base pairs to the Watson-Crick duplex are also interesting approaches that have demonstrated increased recognition efficiency.

Triplex formation is observed at certain polypurine-polypyrimidine sequences that are widely found in the human genome, particularly at promoter regions [26-29]. Several published studies have described the triplex-stabilizing features of 8-aminopurines and the use of parallel and antiparallel tail-clamps to improve the efficacy of triplex recognition with complementary RNA and DNA targets $[30,31]$. On that regard, this triplex hybridization has been effectively applied to develop biosensors. For example, Carrascosa et al. and Aviñó et al. developed a sensitive and label-free method for the detection of an mRNA from Listeria and miRNA-145 by the formation of triplex hybridization structures in SPR biosensors [32]. More recently, Wei et al. have reported a method that combines the formation of triplex DNA structures with further amplification reactions for the sensitive detection of microRNAs [33] and some of us have developed an oligonucleotide-gated mesoporous support for the identification of miRNA-145 based on the formation of triple-helix structure, allowing a sensitivity as low as $2.5 \mathrm{pM}$ and accurate qualitative determination in human serum samples [34].

Based on the above, we report herein two probes for the specific identification of $P$. jirovecii using gated nanomaterials. The diagnostic tool is based in NAA, whose pores are loaded with the fluorophore rhodamine B and blocked with different oligonucleotide probes (single or hairpin strands, see Scheme S1) able to form duplex or triplex structures with the target gene of mtLSUrRNA of $P$. jirovecii DNA. Best analytical performances are obtained for the triplex hybridization with a LOD of $1 \mathrm{nM}$ in less than one hour without previous DNA amplification. Likewise, this method detects $P$. jirovecii DNA in unmodified sputum, nasopharyngeal aspirates (NPA), and bronchoalveolar lavage (BAL) samples, showing its great potential in point-of-care applications.

\section{Materials and Methods}

\subsection{General Techniques}

A ZEISS Ultra 55 microscope was employed to perform field emission scanning electron microscopy (FSEM) and energy dispersive X-ray spectroscopy (EDX) analyses. Fluorescence spectroscopy measurements were carried out on a Synergy H1 microplate reader (BioTek, Winooski, VT, USA).

\subsection{Chemicals}

Tris(hydroxymethyl)aminomethane (TRIS), hydrochloric acid, (3-aminopropyl)triethoxysilane (APTES), and rhodamine B, were obtained from Sigma-Aldrich Quimica (Madrid, Spain). NAA scaffolds were purchased from InRedox (Longmont, CO, USA). 


\subsection{Synthesis of Oligonucleotides}

In this study it was used the gene encoding the mitochondrial large-subunit of P. jirovecii (mt LSU rRNA). Design of oligonucleotides and in silico analysis is described in the Electronic Supplementary Information (Scheme S1). Table 1 shows the sequences of the oligonucleotides employed in this study. The synthesis took place by the well-defined phosphoramidite solid phase protocol [32]. For this, oligonucleotides were assembled on controlled pore glass (CPG) scaffolds by consecutive incorporation of the suitable phosphoramidites employing an automated Applied Biosystems 394 DNA synthesizer (Foster City, CA, USA). Then, the scaffolds were treated overnight with concentrated ammonia at $55^{\circ} \mathrm{C}$. Finally, synthetized oligonucleotides were purified by Glen-PackTM DNA cartridges (Glen Research, Sterling, VA, USA) and mass spectrometry was used to analyze them (Table S1, ESI).

Table 1. Sequences of the used oligonucleotides.

\begin{tabular}{|c|c|c|}
\hline & Oligonucleotide & Sequence $\left(5^{\prime}-3^{\prime}\right)$ \\
\hline O1 & Duplex antiparallel & 5'-GAAAGGGAAACAGCCCAG-3' \\
\hline $\mathrm{O} 2$ & Clamp antiparallel & $\begin{array}{l}\text { 5'-GACAAAGGGAAAG-TTTT- } \\
\text { GAAAGGGAAACAGCCCAG-3' }\end{array}$ \\
\hline $\mathrm{O} 3$ & Control clamp antiparallel & $\begin{array}{l}\text { 5'-AGAGCAGAAAGGA-TTTT- } \\
\text { GAAAGGGAAACAGCCCAG-3' }\end{array}$ \\
\hline $\mathrm{O} 4$ & Target complementary & 5'-CTGGGCTGTTTCCCTTTC-3' \\
\hline
\end{tabular}

\subsection{Synthesis of Nanomaterials S0, S1 (Duplex), S2 (Clamp), and S3 (Control)}

For the synthesis of S0, 10 individual NAA scaffolds ( $2 \mathrm{~mm}$ of diameter each one) were submerged in a solution of rhodamine $\mathrm{B}$ in $\mathrm{CH}_{3} \mathrm{CN}(1 \mathrm{mM}, 8 \mathrm{~mL})$. The mixture was stirred at room temperature for $24 \mathrm{~h}$. Then the functionalization of the surface with aminopropyl moieties was carried out by adding $40 \mu \mathrm{L}$ per individual NAA scaffold of (3-aminopropyl)triethoxysilane $(1.25 \mu \mathrm{M})$ and stirring the mixture at room temperature for $6 \mathrm{~h}$. For the synthesis of the sensing probes $\mathbf{S 1}, \mathbf{S 2}$, and $\mathbf{S 3}$, different pieces of solid S0 were capped by adding to each support $10 \mu \mathrm{L}$ of the corresponding oligonucleotide (O1, O2, or O3, respectively) $(100 \mu \mathrm{M})$ in a final volume of $250 \mu \mathrm{L}$ of hybridization buffer $(20 \mathrm{mM}$ Tris- $\left.\mathrm{HCl}, 37.5 \mathrm{mM} \mathrm{MgCl}_{2}, \mathrm{pH} 7.5\right)$. The mixtures were shaken for $60 \mathrm{~min}$ at $37^{\circ} \mathrm{C}$. The capped materials were rinsed with hybridization buffer to remove the unbounded oligonucleotide.

\subsection{Release Kinetics}

The response of the gated materials was determined by measuring the fluorescence of the dye released from the pores to the solution in the presence of the target complementary DNA. In a common experiment, two independent supports of each material S1, S2, and S3 were immersed in $900 \mu \mathrm{L}$ of hybridization buffer. Then, $100 \mu \mathrm{L}$ of the complementary DNA $(10 \mu \mathrm{M})$ was added to one of the supports while $100 \mu \mathrm{L}$ of hybridization buffer was added to the other. Both solutions were stirred at $37^{\circ} \mathrm{C}$ and aliquots were taken at scheduled times. Finally, dye delivery was determined by registering the fluorescence of the rhodamine $B$ in the solution at $575 \mathrm{~nm}\left(\lambda_{\text {exc }}=555 \mathrm{~nm}\right)$.

\subsection{Real Media Experiments}

The response of $\mathbf{S} 2$ was assessed in a more realistic context. For that, $500 \mu \mathrm{L}$ of sputum, bronchoalveolar lavage (BAL) and nasopharyngeal aspirate (NPA) samples were artificially inoculated with $100 \mu \mathrm{L}$ of DNA from $P$. jirovecii $(10 \mu \mathrm{M})$ and added to two independent S2 supports in a final volume of $1 \mathrm{~mL}$ in hybridization buffer. Solutions were maintained at $37^{\circ} \mathrm{C}$ and rhodamine B released from the pores was measured at $575 \mathrm{~nm}\left(\lambda_{\mathrm{exc}}=555 \mathrm{~nm}\right)$ after $60 \mathrm{~min}$.

\subsection{Response to Different Target Concentrations}

The response of the material S2 to different concentrations of the target DNA was assessed. For this, six independent supports were submerged separately in $900 \mu \mathrm{L}$ of hybridization buffer and 
$100 \mu \mathrm{L}$ of 10 -fold diluted target solutions were added to each one, reaching final concentrations from $10^{-5}$ to $1 \mu \mathrm{M}$. After $60 \mathrm{~min}$ at $37^{\circ} \mathrm{C}$, the released rhodamine B from the porous was measured at $575 \mathrm{~nm}$ $\left(\lambda_{\text {exc }} 555 \mathrm{~nm}\right)$.

\subsection{Selectivity to Possible Interferents}

The selectivity of the method was determined for $\mathbf{S} 2$ by carrying out cargo delivery experiments in the presence of $100 \mu \mathrm{L}$ of DNA (10 ng/ $\mu \mathrm{L}$ ) from other microorganisms (Aspergillus spp., Candida albicans, Candida tropicalis, Candida auris, Schizosaccharomyces pompe, and Taphrina deformans) in a final reaction volume of $1 \mathrm{~mL}$ of hybridization buffer. In the same experiment, $100 \mu \mathrm{L}$ of complementary DNA from P. jirovecii at $10 \mathrm{ng} / \mu \mathrm{L}$ was used as a positive control and $100 \mu \mathrm{L}$ of hybridization buffer as a negative control. Mixtures were maintained in agitation for $60 \mathrm{~min}$ at $37^{\circ} \mathrm{C}$ and the delivered rhodamine $\mathrm{B}$ was determined by measuring the fluorescence in the solution $\left(\lambda_{\mathrm{exc}}=555 \mathrm{~nm}, \lambda_{\mathrm{em}}=585 \mathrm{~nm}\right)$.

\subsection{Validation of the Method in Clinical Samples}

In order to determine the clinical applicability of the gated nanosensor, the performance of $\mathbf{S} 2$ was evaluated in a more realistic media. First, the system was used to analyze 8 sputa and 4 bronchoalveolar lavages (BAL) from infected and non-infected patients from the Hospital Universitari i Politècnic La Fe. In another experiment, 21 nasopharyngeal aspirates (NPA) from colonized and non-colonized newborn infants from the Hospital Universitario Virgen del Rocío were analyzed using S2 nanomaterials. For both assays, $250 \mu \mathrm{L}$ of each sample were added to individual S2 solids in a final volume of $400 \mu \mathrm{L}$ of hybridization buffer. After $60 \mathrm{~min}$ at $37^{\circ} \mathrm{C}$, dye released from the pores to the solution was measured by fluorescence spectroscopy at $575 \mathrm{~nm}\left(\lambda_{\text {exc }} 555 \mathrm{~nm}\right)$.

\section{Results and Discussion}

\subsection{Synthesis and Characterization of the Biosensors}

Figure 1 depicts the synthetic process followed to obtain the biosensors and their performance in the presence of the target DNA. NAA scaffolds were selected as inorganic supports to develop the capped nanomaterials. First, pores were filled with the dye rhodamine B which has demonstrated excellent properties for the preparation of optical gated nanosensors applied to the detection of different analytes [18-26]. In a second step, the outer surface of the NAA support was functionalized with the linker (3-aminopropyl)triethoxysilane, yielding S0. At a neutral $\mathrm{pH}$, aminopropyl moieties are partially protonated (and therefore positively charged) being able to electrostatically interact with negatively charged oligonucleotides. Based on this, the interaction of oligonucleotides $\mathbf{O 1}, \mathbf{O} 2$, or $\mathbf{O} 3$ with the amino-functionalized S0, yielded the gated sensing solids S1, S2, and S3. O1 consists of a single strand oligonucleotide that hybridizes with the DNA sequence forming a duplex structure, $\mathbf{O} 2$ is a clamp that forms a triplex hybridization structure, whereas $\mathbf{O} 3$ is also a clamp but results in a duplex conformation.

The recognition and detection mechanism of the loaded and capped S1, S2, and S3 materials takes place as follows. In the absence of target analyte, the oligonucleotides $\mathbf{O 1}, \mathbf{O 2}$, or $\mathbf{O 3}$, electrostatically attached to the external surface of the inorganic scaffold, were expected to be bulky enough to block pores and to inhibit dye delivery. On the contrary, due to the higher affinity of the oligonucleotide probes for the target than for the aminopropyl moieties, it was expected that in the presence of the analyte, the capping oligonucleotides were selectively displaced from the surface resulting in DNA target-probe hybridization, pore opening and dye diffusion from the pores to the aqueous solution. Finally, the used solids were calcined to remove organic matter, allowing supports to be used again (Figure 1).

The starting NAA supports were commercially obtained from InRedox ${ }^{\circledR}$ (Longmont, CO, USA). The supports are anodic aluminum oxide (AAO) films grown on a $0.1 \mathrm{~mm}$ thick aluminum layer with a pore density of $9 \cdot 10^{11} \mathrm{~cm}^{-2}$. Pore entrance has a funnel-like form which gradually decreases from 
a larger size (20-30 nm) at the top of the funnel to a $5 \mathrm{~nm}$ size at the end. Pores have a profundity of ca. $10 \mu \mathrm{m}$. The starting NAA scaffold and S1, S2, and S3 were characterized following standard techniques such as FESEM and EDX analysis. FESEM images of the starting NAA scaffolds confirmed the expected non-ordered porous structure, whereas typical imagens of S1, S2, and S3 showed the presence of an organic layer attributed to the capping oligonucleotides (Figure 2). Furthermore, in S1, S2, and S3, the porous structure of the NAA scaffolds can still be seen in some places where the surface was not completely covered, demonstrating that the loading, functionalization, and capping steps did not modify the NAA structure. This behavior agrees with that observed in previous studies carried out with the same or similar materials [35-37].

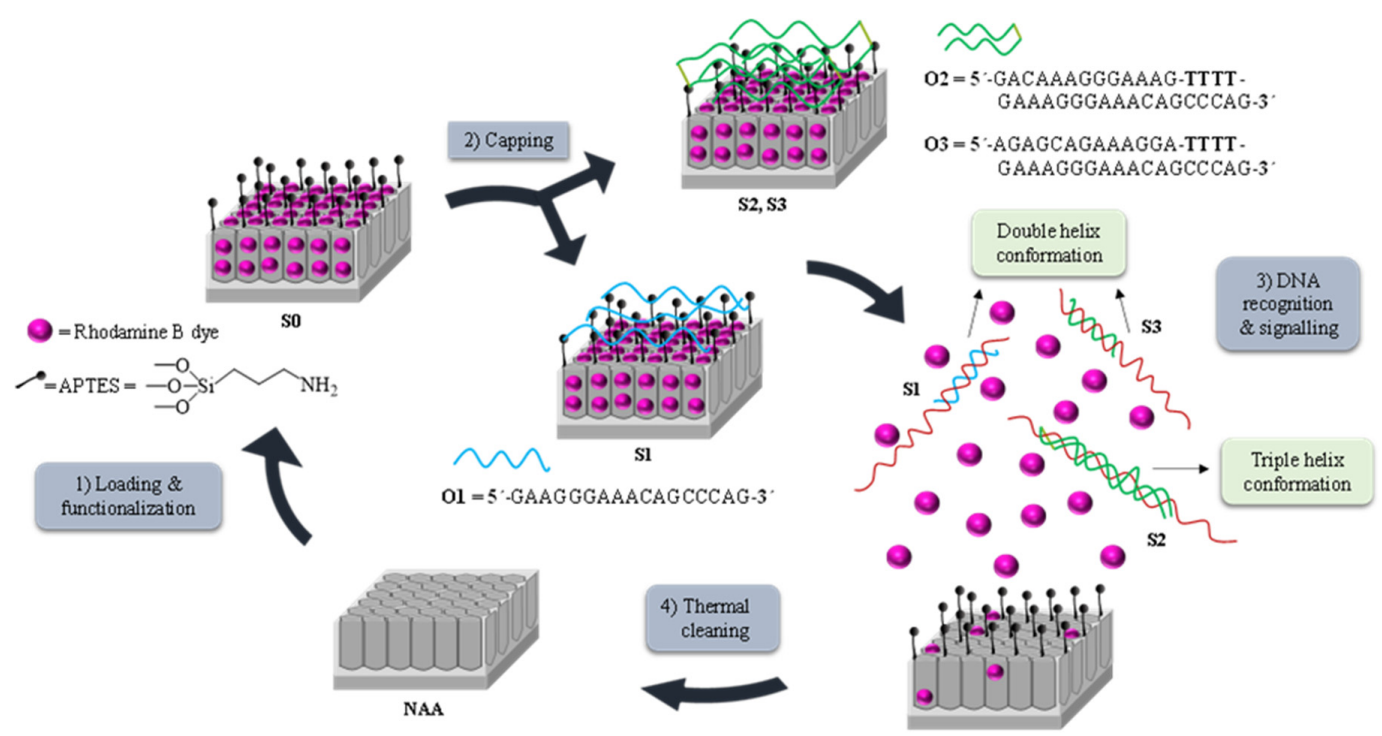

Figure 1. Representation of the preparation and sensing process: (1) Loading and functionalization of the nanoporous anodic alumina (NAA) support; (2) Capping with the oligonucleotides O1, O2, or O3, to obtain solids S1, S2, and S3, respectively; (3) Release of the cargo in the presence of $P$. jirovecii genomic DNA by forming (A) duplex structures when using solids S1 or S3 or (B) triplex hybridization structures when using S2 and (4) Calcination prior to the reutilization of the scaffold.

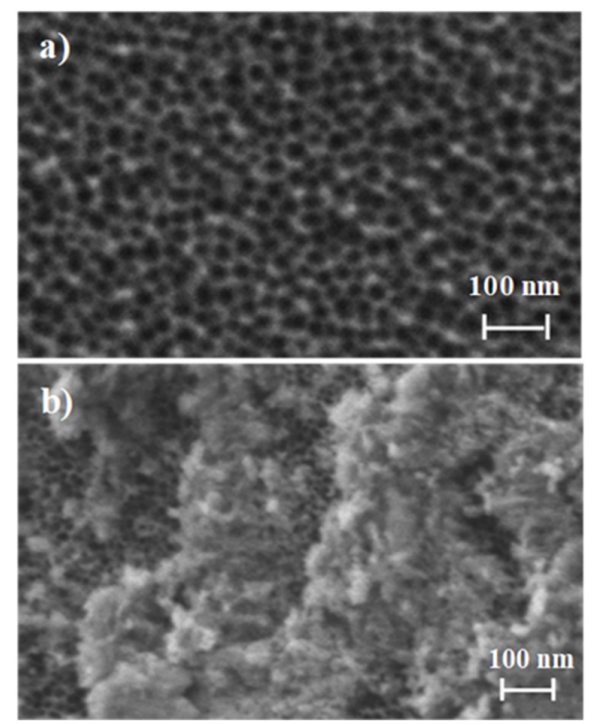

Figure 2. Representation of the preparation and sensing process: (a) Loading and functionalization of the NAA support; (b) Capping with the oligonucleotides. 
The organic content of the different prepared materials (S0, S1, S2, and S3) was studied by energy dispersive X-ray spectroscopy (EDX) (Table 2). After dye loading and surface functionalization with aminopropyl moieties, solid S0 shows a high C/Al content, which was reduced in S1, S2, and S3 due to the partial rhodamine $B$ release that takes place during the gating process. Moreover, the existence of nitrogen in all final solids is indicative of the presence of aminopropyl groups and oligonucleotides. The occurrence of the latter is also confirmed by the presence of phosphorous atoms.

Table 2. Atomic elements ratio in the different prepared solids by energy dispersive $\mathrm{X}$-ray spectroscopy (EDX) studies.

\begin{tabular}{lccc}
\hline & C/A1 & N/A1 & P/Al \\
\hline S0 & 1.52 & 0.38 & - \\
S1 & 0.76 & 0.40 & 0.01 \\
S2 & 0.58 & 0.53 & 0.02 \\
S3 & 0.74 & 0.42 & 0.02 \\
\hline
\end{tabular}

\subsection{Delivery Kinetics}

In a first step, the response of the nanoprobes $\mathbf{S 1}, \mathbf{S 2}$, and $\mathbf{S 3}$ to the presence of the target sequence O4 was studied. In a typical experiment, two individual solids of each material S1-S3 were submerged in hybridization buffer. Then, $100 \mu \mathrm{L}$ of the complementary oligonucleotide sequence $\left(\mathbf{O} 4,1 \mathrm{ng} \mu \mathrm{L}^{-1}\right)$ were transferred to one of the supports while $100 \mu \mathrm{L}$ of buffer were added to the other. Mixtures were stirred at $37^{\circ} \mathrm{C}$ and at predetermined times (i.e., 15, 30, 45, and $60 \mathrm{~min}$ ) the fluorescence of the solution was measured to quantify the amount of the dye delivered from the pores to the aqueous phase. As an example, Figure 3 shows the delivery profile for solid S2. When the target sequence $\mathbf{O} 4$ was present, a remarkable dye delivery from the pores to the solution was observed as a result of the oligonucleotide-DNA hybridization to form a DNA triplex structure (curve b), pore opening and dye release. The maximum dye diffusion from the pores to the solution was reached at $60 \mathrm{~min}$ and this value was considered the $100 \%$ of delivered dye. On the contrary, in the lack of the $\mathbf{O} 4$ sequence, a very low dye is released, what indicates tight pore blockage by the probes electrostatically attached to the scaffold surface (curve a).

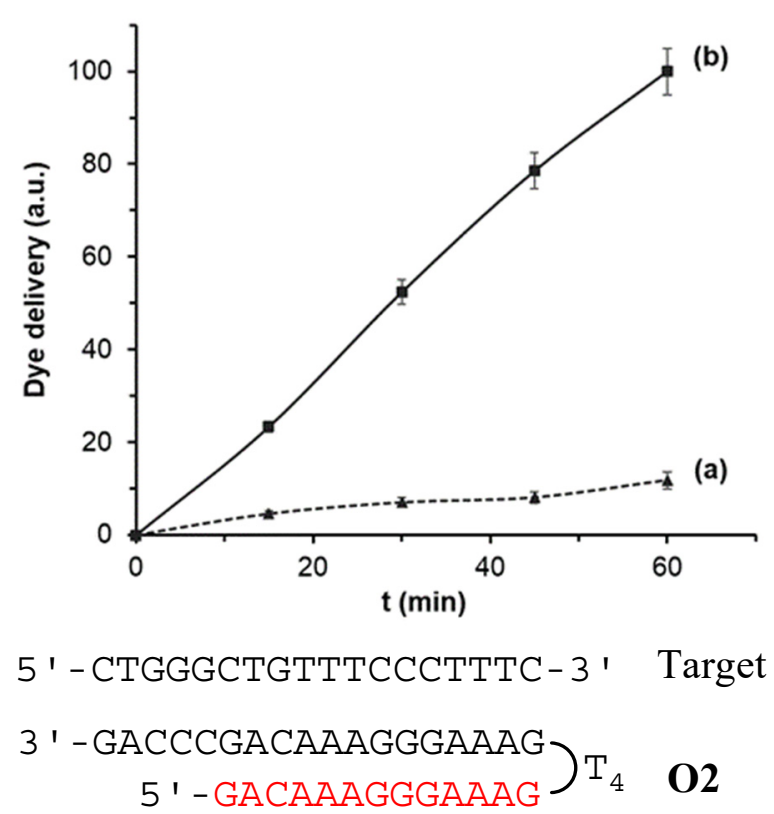

Figure 3. Rhodamine B delivery from S2 (a) in the absence and (b) in the presence of $1 \mathrm{nM}$ of complementary $\mathbf{O} 4$ target sequence in a solution of hybridization buffer $(20 \mathrm{mM}$ Tris- $\mathrm{HCl}, 37.5 \mathrm{mM}$ $\left.\mathrm{MgCl}_{2}, \mathrm{pH} 7.5\right)$. 
Similar delivery profiles were observed for solids $\mathbf{S} \mathbf{1}$ and $\mathbf{S} 3$, also indicating adequate performance for these solids in the stages of DNA recognition and dye release (Figure S1, ESI). In terms of blockage ability, all three developed systems were able to keep the pore entrances closed regardless the capping oligonucleotide was a clamp (S2 and S3) or a single strand, obtaining in all cases a very low residual dye delivery (lower than $20 \%$ ) in the absence of $\mathbf{O} 4$ target sequence.

All three nanodevices were also able to deliver the cargo in the presence of target sequence $\mathbf{O} 4$. However, differences in terms of the amount of dye delivered were observed when comparing the formation of triplex (S2) and duplex hybridization (S1 and S3) structures. The obtained results showed that nanomaterial S2 provided a faster response and the highest cargo release, reaching a first order constant rate of the release kinetics of 1.70 and an amount of ca. $2.8 \mathrm{ng}$ of delivered Rhodamine B, calculated by interpolating the fluorescence of the amount of dye diffused from the pores to the solution after 60 min into a calibration curve of Rhodamine B. On the other hand, for S1 and S3 materials, the uncapping mechanism and subsequent dye release was slower (constant rates of 1.16 and 1.14, respectively), and the amount of dye delivered at $60 \mathrm{~min}$ was lower (by ca. $20 \%$ ). This in tentatively attributed to a more stable, favorable and rapid formation of the triplex structure than those obtained by the duplex conformations (S1 and S3). These results agree with others found in the literature in which the efficiency and stability of triplex hybridization structures were higher than those obtained by duplex conformations $[33,34]$ Therefore, further studies were carried out using $\mathbf{S 2}$ as sensing material.

\subsection{Analytical Performance: Sensitivity and Specificity Studies}

New diagnostic tools should be evaluated in terms of limit of detection (LOD) and specificity. The LOD in $\mathbf{S 2}$ was determined via the study of the response of the gated material to the presence of different amounts of target sequence $\mathbf{O}$. Based on the proposed sensing mechanism, the amount of released dye depends on the number of opened pores, which in turn depends on the number of target molecules that will induce the displacement of the capping molecules. Results depicted in Figure 4A show that the amount of delivered dye was directly proportional to the target DNA concentration, which agrees with the uncapping protocol detailed above. A LOD of $1 \pm 0.1 \mathrm{nM}$ was calculated based on the intersection point of the two slopes of the represented curve (Figure 4A). This LOD value is in the range of other reported protocols for the detection of $P$. jirovecii genomic DNA. Thus, for instance, several works based on the diagnosis of PcP by real time PCR reported LODs of 50-200 copies/ $\mu \mathrm{L}$, which corresponds to a DNA concentration range from ca. $250 \mathrm{pM}$ to $1 \mathrm{nM}$. However, our system is faster, simpler, and requires no especial equipment or trained personnel [38-43].

A)

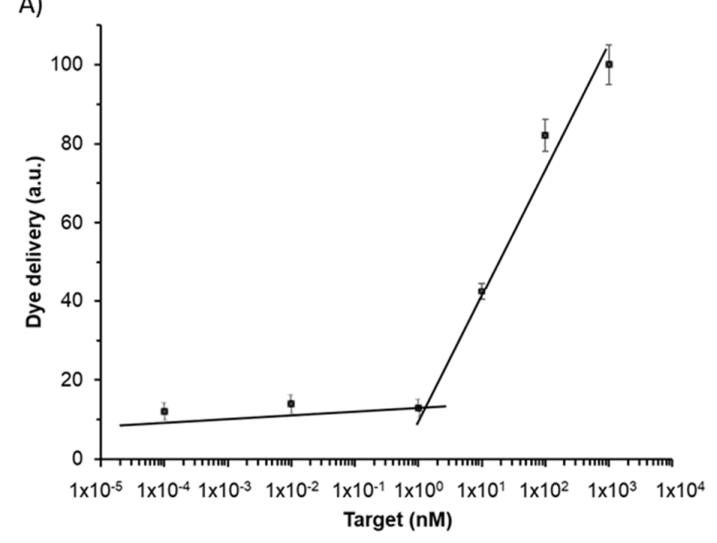

B)

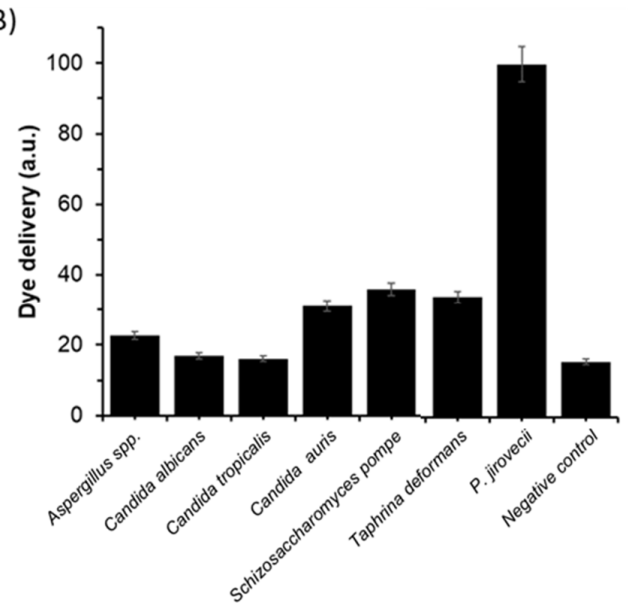

Figure 4. Release of rhodamine B from solid S2 (A) in the presence of different concentrations of $\mathbf{O} 4$ and (B) in the presence of $1 \mathrm{ng} / \mu \mathrm{L}$ of genomic DNA from Aspergillus spp., C. albicans, C. tropicalis, C. auris, S. pompe, T. deformans, P. jirovecii, and $100 \mu \mathrm{L}$ of hybridization buffer as a negative control. Assays were performed at $60 \mathrm{~min}$ in hybridization buffer at $\mathrm{pH} 7.5$. 
The specificity of the system was evaluated by assessing the response of $\mathbf{S} 2$ to the presence of genomic DNA from other fungi considered as possible interferents, such as Aspergillus spp., C. albicans, C. tropicalis, C. auris, S. pompe, and T. deformans. For that, the amount of dye delivered from the pores of seven independent $\mathbf{S} 2$ supports was measured in the presence of $100 \mu \mathrm{L}$ of DNA at $10 \mathrm{ng} / \mu \mathrm{L}$ of each possible interferent. Moreover, $100 \mu \mathrm{L}$ of DNA from target $\mathrm{O} 4$ at $10 \mathrm{ng} / \mu \mathrm{L}$ and $100 \mu \mathrm{L}$ of hybridization buffer were added to $\mathbf{S} 2$ as positive and negative control, respectively. As it is shown in Figure 4B, target sequence $\mathbf{O 4}$, present in P. jirovecii genomic DNA, is the only capable of induce a notable pore opening and rhodamine $B$ release, whereas all the other fungi induced less response and lower dye release. That results confirmed the high selectivity of the system, even in the presence of DNA from S. pompe and T. deformans, which belongs to the same subphylum as Pneumocystis genus [44].

In a step forward, the robustness of the system was determined by evaluating the behavior of $\mathbf{S 2}$ to the presence of the target sequence $\mathbf{O} 4(0.1 \mathrm{ng} / \mu \mathrm{L})$ in different respiratory fluids such as sputum, bronchoalveolar lavage (BAL) and nasopharyngeal aspirate (NPA) (Figure S2, ESI). In all media, the presence of $\mathbf{O} 4$ produced a selective displacement of the oligonucleotide in $\mathbf{S 2}$, pore uncapping and dye delivery, whereas in the absence of target, a poor dye release was observed. A lower signal intensity was found in the sputum than in the BAL, NPA, and buffer media (60\% vs. $100 \%)$, probably due to the higher complexity of the sputum samples. Nevertheless, the amount of dye delivered in all cases and the differences with respect to control samples (not having target $\mathbf{O} 4$ sequence) is significant, allowing an accurate fungi DNA detection in all the samples (Figure S2, ESI). These results show that the proposed method may be a promising alternative to classical procedures for the detection of DNA from $P$. jirovecii in realistic environments.

In addition, it is worth mentioning that previous studies have demonstrated the possible re-use of these type of gated nanomaterials [25,36]. In this respect, used NAA supports were calcined to remove organic matter and reused up to 3 times for the detection of $\mathrm{O} 4$ obtaining similar results.

\subsection{P. jirovecii Detection in Clinical Samples}

Once the method was analytically studied, a clinical validation is required to determine the real utility of the sensing material S2 as a tool for the diagnosis of PcP produced by the infection of P. jirovecii as a possible alternative to existing conventional methods. The gold standard procedure used in most hospitals to diagnose PcP uses extraction of the genomic DNA from the fungus and its subsequent amplification by PCR techniques.

In the present study, 12 respiratory samples consisting of sputum and BAL samples from infected and non-infected patients from Hospital Universitari i Politècnic La Fe, were analyzed using S2 material and the hospital reference method (i.e., PCR). For that, samples were isolated from patients with respiratory symptoms as part of routine diagnosis treatment. All samples were analyzed by PCR for the detection of $P$. jirovecii genomic DNA. Extraction of DNA from the samples was carried out by the QIAamp DNA Blood and Tissue kit and PCR reactions were performed using the VIASURE P. jirovecii Real Time PCR Detection Kit. Following this procedure, ten samples were confirmed as positive and two resulted negative. In parallel, the same samples (i.e., unmodified sputum or BAL samples) were tested using S2. For that, 12 individual S2 supports were immersed in $150 \mu \mathrm{L}$ of hybridization buffer, then $250 \mu \mathrm{L}$ of each raw sample were directly added without any previous treatment and the fluorescence in the solution, due to rhodamine delivery, was measured after $60 \mathrm{~min}$. Results were considered positives when the fluorescence intensity was higher than the average fluorescence of the negative controls plus three times their standard deviation. As shown in Table 2 (samples 1 to 12), the results show a total coincidence between both methods, obtaining a sensitivity and a specificity of the $100 \%$, and therefore, positive and negative predictive values of $100 \%$, demonstrating an excellent analytical and clinical results when using $\mathbf{S} 2$ as diagnostic tool.

On the other hand, $\mathbf{S} 2$ was employed to evaluate 21 NPA samples from newborn infants with and without primary Pneumocystis infection from Hospital Universitario Virgen del Rocío. First, all samples were analyzed by Nested-PCR of the Pneumocystis mtLSU rRNA gene as described elsewhere [6]. 
Briefly, DNA from P. jirovecii was extracted using a QIAmp DNA Mini Kit with proteinase K digestion at $56^{\circ} \mathrm{C}$. In the first round of amplification, the external primers pAZ102-E and pAZ102-H were used. This yielded a 346-base pair (bp) fragment. The second round utilized the internal primers pAZ102-X and pAZ102-Y and yielded a 260-bp product. Both rounds of PCR comprised 35 amplification cycles. Specific amplification was corroborated by melting curve analysis (Tm: $76-77^{\circ} \mathrm{C}$ ) and amplicons were analyzed by electrophoresis on a $1.5 \%$ agarose gel containing ethidium bromide. Following this procedure, 11 samples were confirmed as positive and 10 resulted negative.

Nested-PCR positive samples were quantified by qPCR. Real-time quantitative PCR was performed in a CFX96 real time system (BIO-RAD) using AceQ qPCR SYBR ${ }^{\circledR}$ Green Master Mix (Vazyme) in a final volume of $10 \mu \mathrm{L}$ containing $0.2 \mathrm{mM}$ of primers pAZ102-X and pAZ102-Y and $2 \mu \mathrm{L}$ of DNA sample. Serial dilutions of the target sequence cloned in the pGEM-T Easy Vector (Promega) were used to generate standard curves. After quantification, all the samples showed less than $10^{2}$ copies $/ \mu \mathrm{L}$, which is equivalent to less than 25,000 copies per $\mathrm{mL}$ of NPA. That concentration confirms the $P$. jirovecii colonization condition and agrees with normal concentrations found in NPA samples from newborns with primary Pneumocystis infection [45].

In parallel, the same samples (i.e., unmodified NPA samples) were analyzed using S2. For that, 21 individual S2 supports were submerged in $150 \mu \mathrm{L}$ of hybridization buffer and $250 \mu \mathrm{L}$ of of each raw sample were directly added without any previous treatment. Finally, the fluorescence of the solution was measured after $60 \mathrm{~min}$ and results were considered positives when the fluorescence intensity was higher than the average fluorescence of the negative controls plus three times their standard deviation. As it is depicted in Table 3 (samples 13 to 33), results showed the coincidence between two methods in 16 samples and a total of 5 incongruent values that corresponded to two false positives and three false negatives, gave a sensitivity of $70 \%$, a specificity of $78 \%$, and positive and negative predictive values of $78 \%$ and $70 \%$, respectively. The incongruences observed between the results obtained by PCR and S2 materials might be due several causes such as sample handling, DNA degradation or the very low concentration of pathogen present in NPA samples (calculated as less than 25,000 copies per $\mathrm{mL}$ of NPA). Nevertheless, it is noteworthy the high competitiveness of the gated biosensor as rapid diagnostic tool compared to the standard reference procedures, additionally providing easiness to use and lower cost, and avoiding sample treatments such as DNA extraction steps or amplification reactions [46].

Table 3. Detection of $P$. jirovecii in clinical samples using the reference method (PCR) and S2 material. Each sample was analyzed by triplicate.

\begin{tabular}{ccccc}
\hline \multirow{2}{*}{ Sample $^{\mathbf{a}}$} & \multirow{2}{*}{ Biological Fluid } & \multicolumn{2}{c}{ Reference Method (PCR) } & $\mathbf{S}^{\mathbf{b}}$ \\
\cline { 3 - 5 } & & $\mathbf{C t}$ & Result & Result $^{\mathbf{c}}$ \\
\hline 1 & Sputum & 28 & Infected & + \\
2 & Sputum & 27.5 & Infected & + \\
3 & BAL & 36.6 & Infected & + \\
4 & Sputum & 28.5 & Infected & + \\
5 & BAL & 38.8 & Infected & + \\
6 & BAL & 19 & Infected & + \\
7 & Sputum & 26.8 & Infected & + \\
8 & Sputum & 30.28 & Infected & + \\
9 & Sputum & 35.3 & Infected & + \\
10 & Sputum & 34.9 & Infected & + \\
11 & BAL & $>40$ & Non-Infected & - \\
12 & Sputum & $>40$ & Non-Infected & - \\
13 & NPA & - & Non- Infected & - \\
14 & NPA & - & Non- Infected & - \\
15 & NPA & - & Non- Infected & - \\
\hline
\end{tabular}


Table 3. Cont.

\begin{tabular}{ccccc}
\hline \multirow{2}{*}{ Sample $^{\mathbf{a}}$} & \multirow{2}{*}{ Biological Fluid } & \multicolumn{2}{c}{ Reference Method (PCR) } & $\mathbf{S 2}^{\mathbf{c}}$ \\
\cline { 3 - 5 } & & $\mathbf{C t}$ & Result & Result $^{\mathbf{c}}$ \\
\hline 16 & NPA & 33.6 & Infected & + \\
17 & NPA & 37.2 & Infected & + \\
18 & NPA & 34.9 & Infected & + \\
19 & NPA & 28.8 & Infected & + \\
20 & NPA & - & Non- Infected & - \\
21 & NPA & 33.4 & Infected & + \\
22 & NPA & - & Non- Infected & - \\
23 & NPA & - & Non- Infected & - \\
24 & NPA & - & Non- Infected & - \\
25 & NPA & - & Non- Infected & + \\
26 & NPA & - & Non- Infected & + \\
27 & NPA & - & Non- Infected & - \\
28 & NPA & 34.9 & Infected & - \\
29 & NPA & 39.4 & Infected & - \\
30 & NPA & 34.4 & Infected & + \\
31 & NPA & 34.6 & Infected & + \\
32 & NPA & 33.4 & Infected & + \\
33 & NPA & 35.5 & Infected & - \\
\hline
\end{tabular}

a Samples 1 to 12 were from patients of Hospital Universitari i Politècnic La Fe and samples 13 to 33 were from newborn infant patients of Hospital Universitario Virgen del Rocío. ${ }^{b}$ Samples were considered positives (+) when two different aliquots of each patient were positive by specific PCR for $P$. jirovecii. ${ }^{c}$ Samples were considered positives $(+)$ when the fluorescence signal at $585 \mathrm{~nm}\left(\lambda_{\mathrm{exc}}=555 \mathrm{~nm}\right)$ was higher than the average fluorescence of the negative controls plus three times the standard deviation.

\section{Conclusions}

Early diagnosis of $\mathrm{PcP}$ is decisive for a suitable treatment and for a better prognosis. In that regard, rapid and accurate diagnostic tools are important for an early identification of the pathogen and to reduce the risk of mortality associated. However, standard diagnosis of $\mathrm{PcP}$ in remote or less developed countries or in resource-limited settings is difficult as usually it is necessary the use of costly well-equipped laboratories and trained personnel. In this scenario, the design low-cost easy-to-use diagnostic systems and point-of-care devices from readily accessible bio-fluids constitute a potential solution. In this study, a new method for the detection of P. jirovecii genomic DNA by using gated nanomaterials is proposed. In the developed tool, the pores of a NAA scaffold are loaded with a dye and gated with oligonucleotides that selectively recognizes a sequence of the genomic DNA from the fungi. The sensing mechanism relies in the recognition between the gating oligonucleotides and the P. jirovecii genomic DNA that induces a displacement of the capping oligonucleotide, pore uncapping and cargo delivery. In addition, the use of different gating oligonucleotides in the form of single strands or clamps to obtain duplex or triple-helix hybridization structures is also studied. From the three evaluated nanomaterials (S1, S2, and S3), the solid S2 provides the highest rhodamine B release and the faster response, probably due to more efficient formation of a triplex with respect to duplex conformations (S1 and S3). S2 showed a LOD $1 \mathrm{nM}$ in hybridization buffer, which is equivalent to other state-of-the-art reported detection systems. Moreover, the probe presented a high selectivity to $P$. jirovecii, since no response was observed in the presence of DNA from other microorganisms. Finally, the gated material $\mathbf{S 2}$ is tested in unmodified sputum and bronchoalveolar lavages samples from infected and non-infected patients to diagnose PcP, obtaining a sensitivity and a selectivity of $100 \%$. In the same way, $\mathbf{S} \mathbf{2}$ is used to analyze nasopharyngeal aspirate samples from infants to detect primary infected individuals with a sensitivity and a selectivity of $70 \%$ and $78 \%$, respectively. In both cases, S2 detects $P$. jirovecii in 60 min without any sample treatment or the use of amplification reactions. This diagnostic tool has great potential for the further development of point-of-care devices for the 
simple and accurate detection of $P$. jirovecii from different biofluids avoiding PCR and using a small amount of sample, which could represent a high gain in the fight against PcP.

Supplementary Materials: The following are available online at http://www.mdpi.com/2309-608X/6/4/292/s1, Scheme S1: Scheme of the duplexes formed by oligonucleotides O1 and O3 with the target, and the triplex formed by oligonucleotide $\mathrm{O} 2$ and the target sequence, Table S1: Mass spectrometry analysis of the oligonucleotides, Figure S1: Amount of rhodamine B released from the pores of solids S1 (A) and S3 (B) when $1 \mathrm{nM}$ of DNA from P. jirovecii was (a) absent and (b) present in a solution of hybridization buffer $(20 \mathrm{mM}$ Tris- $\mathrm{HCl}, 37.5 \mathrm{mM} \mathrm{MgCl}$, $\mathrm{pH}$ 7.5), Figure S2: Delivery of rhodamine B from material S2 in buffer, sputum, BAL, and NPA fluids in the presence of complementary DNA from P. jirovecii $(1 \mathrm{nM})$.

Author Contributions: L.P.: investigation, methodology, writing—original draft; A.A.: investigation, resources, writing—review and editing; R.E.: investigation, resources, writing-review and editing, A.R.-G.: resources, writing — review and editing; J.P.: resources, writing—review and editing; V.F.: resources, writing—review and editing; E.J.C.: resources, writing-review and editing; E.A.: investigation, supervision, funding acquisition, writing - review and editing; R.M.-M.: conceptualization, supervision, funding acquisition, writing - review and editing; and S.S.-F.: investigation, supervision, methodology; writing — original draft, writing — review and editing. All authors have read and agreed to the published version of the manuscript.

Funding: This research was funded by the Spanish Government, (projects RTI2018-100910-B-C41 (MCUI/AEI/FEDER, UE) and CTQ2017-84415-R), the Generalitat Valenciana (project PROMETEO/2018/024) and CIBER-BBN (projects NANOPATH and CANDI-EYE).

Acknowledgments: L.P. thanks UPV for her predoctoral fellowship. S.S. thanks the Instituto de Salud Carlos III and the European Social Fund for the financial support "Sara Borrell" (CD16/000237). The authors also thank the Electron Microscopy Service at the UPV and ICTS NANBIOSIS oligonucleotide synthesis platform (U29) for support. The authors would like to thank Jordi Luque Font, from the IRTA Institute of Agrifood Research and Technology-Cabrils, and Josep Armengol from the Instituto Agroforestal Mediterráneo-Universitat Politècnica de València for the supply of T. deformans samples. The fungal culture of S. pompe was supplied by Piet W.J. de Groot from the Regional Center for Biomedical Research, Castilla-La Mancha Science \& Technology Park, University of Castilla-La Mancha.

Conflicts of Interest: The authors declare no conflict of interest. The funders had no role in the design of the study; in the collection, analyses, or interpretation of data; in the writing of the manuscript, or in the decision to publish the results.

\section{References}

1. Fauchier, T.; Hasseine, L.; Gari-Toussaint, M.; Casanova, V.; Marty, P.M.; Pomares, C. Detection of Pneumocystis jirovecii by Quantitative PCR To Differentiate Colonization and Pneumonia in Immunocompromised HIV-Positive and HIV-Negative Patients. J. Clin. Microbiol. 2016, 54, 1487-1495. [CrossRef] [PubMed]

2. Van de Meer, G.; Brug, S.L. Infection Àpneumocystis Chez L'homme et Chez Les Animax. Annales de la Société Belge de Médecine Tropicale 1942, 22, 301-308.

3. Skalski, J.H.; Kottom, T.J.; Limper, A.H. Pathobiology of Pneumocystis pneumonia: Life cycle, cell wall and cell signal transduction. FEMS Yeast Res. 2015, 15, fov046. [CrossRef] [PubMed]

4. Dellière, S.; Gits-Muselli, M.; Bretagne, S.; Alanio, A. Outbreak-Causing Fungi: Pneumocystis jirovecii. Mycopathologia 2020, 185, 783-800. [CrossRef] [PubMed]

5. Montes-Cano, M.A.; Chabe, M.; Fontillon-Alberdi, M.; De La Horra, C.; Respaldiza, N.; Medrano, F.J.; Varela, J.M.; Dei-Cas, E.; Calderón, E.J. Vertical transmission of Pneumocystis jirovecii in humans. Emergy Infect. Dis. 2009, 15, 125-127. [CrossRef] [PubMed]

6. Jarboui, M.A.; Sellami, A.; Cheikhrouhou, F.; Makni, F.; Ben Arab, N.; Ben Jemaa, M.; Ayadi, A.; Sellami, H. Molecular diagnosis of Pneumocystis jirovecipneumonia in immunocompromised patients. Mycoses 2009, 53, 329-333.

7. Durand-Joly, I.; Chabã, M.; Soula, F.; Delhaes, L.; Camus, D.; Dei-Cas, E.; Chabe, M. Molecular diagnosis ofPneumocystispneumonia. FEMS Immunol. Med. Microbiol. 2005, 45, 405-410. [CrossRef]

8. Song, Y.; Ren, Y.; Wang, X.; Li, R. The biosynthesis pathway of Swainsonine, a new anticancer drug from three endophytic fungi. Med. Mycol. 2016, 57, 111-116. [CrossRef]

9. Tomás, A.L.; Matos, O. Pneumocystis jirovecii Pneumonia: Current Advances in Laboratory Diagnosis. OBM Genet. 2018, 2, 1. [CrossRef]

10. Urabe, N.; Sakamoto, S.; Sano, G.; Ito, A.; Sekiguchi, R.; Homma, S. Serial change in serum biomarkers during treatment of Non-HIV Pneumocystis pneumonia. J. Infect. Chemother. 2019, 25, 936-942. [CrossRef] 
11. Esteves, F.; Calé, S.; Badura, R.; De Boer, M.; Maltez, F.; Calderón, E.; Van Der Reijden, T.; Márquez-Martín, E.; Antunes, F.; Matos, O. Diagnosis of Pneumocystis pneumonia: Evaluation of four serologic biomarkers. Clin. Microbiol. Infect. 2015, 21,379.e1-379.e10. [CrossRef] [PubMed]

12. Tomás, A.L.; Cardoso, F.; Esteves, F.; Matos, O. Serological diagnosis of pneumocystosis: Production of a synthetic recombinant antigen for immunodetection of Pneumocystis jirovecii. Sci. Rep. 2016, 6, 36287-36295. [CrossRef] [PubMed]

13. Arvanitis, M.; Anagnostou, T.; Fuchs, B.B.; Caliendo, A.M.; Mylonakis, E. Molecular and Nonmolecular Diagnostic Methods for Invasive Fungal Infections. Clin. Microbiol. Rev. 2014, 27, 490-526. [CrossRef] [PubMed]

14. Tomás, A.L.; Cardoso, F.; Pinto, M.; de Almeida, M.P.; de Sousa, B.; Pereira, E. In Proceedings of the 28th European Congress of Clinical Microbiology and Infectious Diseases, Madrid, Spain, 21-24 April 2018. Available online: https://www.eurekalert.org/pub_releases/2018-04/esoc-2ec041018.php (accessed on 29 October 2020).

15. Tomás, A.L.; De Almeida, M.P.; Cardoso, F.; Pinto, M.; Pereira, E.; Franco, R.; Matos, O. Development of a Gold Nanoparticle-Based Lateral-Flow Immunoassay for Pneumocystis Pneumonia Serological Diagnosis at Point-of-Care. Front. Microbiol. 2019, 10, 2917. [CrossRef] [PubMed]

16. García-Fernández, A.; Aznar, E.; Martínez-Máñez, R.; Sancenón, F. New Advances in In Vivo Applications of Gated Mesoporous Silica as Drug Delivery Nanocarriers. Small 2020, 16, e1902242. [CrossRef] [PubMed]

17. Aznar, E.; Coll, C.; Marcos, M.D.; Martínez-Máñez, R.; Sancenón, F.; Soto, J.; Amorós, P.; Cano, J.; Ruiz, E. Controlled delivery systems using antibody-capped mesoporous nanocontainers. Chem. Eur. J. 2009, 15, 6877-6888. [CrossRef]

18. Sancenón, F.; Pascual, L.; Oroval, M.; Aznar, E.; Martínez-Máñez, R. Gated Silica Mesoporous Materials in Sensing Applications. ChemistryOpen 2015, 4, 418-437. [CrossRef] [PubMed]

19. Mondragón, L.; Mas, N.; Ferragud, V.; De La Torre, C.; Agostini, A.; Martínez-Máñez, R.; Sancenón, F.; Amorós, P.; Pérez-Payá, E.; Orzáez, M. Enzyme-Responsive Intracellular-Controlled Release Using Silica Mesoporous Nanoparticles Capped with E-Poly-L-lysine. Chem. A Eur. J. 2014, 20, 5271-5281. [CrossRef]

20. Giménez, C.; De La Torre, C.; Gorbe, M.; Aznar, E.; Sancenón, F.; Murguía, J.R.; Martínez-Máñez, R.; Marcos, M.D.; Amorós, P. Gated Mesoporous Silica Nanoparticles for the Controlled Delivery of Drugs in Cancer Cells. Langmuir 2015, 31, 3753-3762. [CrossRef]

21. Aznar, E.; Villalonga, R.; Giménez, C.; Sancenón, F.; Marcos, M.D.; Martínez-Máñez, R.; Díez, P.; Pingarrón, J.M.; Amorós, P. Glucose-triggered release using enzyme-gated mesoporous silica nanoparticles. Chem. Commun. 2013, 49, 6391-6393. [CrossRef]

22. Ouyang, C.; Zhang, S.; Xue, C.; Yu, X.; Xu, H.; Wang, Z.; Lu, Y.; Wu, Z.-S. Precision-Guided Missile-Like DNA Nanostructure Containing Warhead and Guidance Control for Aptamer-Based Targeted Drug Delivery into Cancer Cells in Vitro and in Vivo. J. Am. Chem. Soc. 2020, 142, 1265-1277. [CrossRef] [PubMed]

23. Argoubi, W.; Sánchez, A.; Parrado, C.; Raouafi, N.; Villalonga, R. Label-free electrochemical aptasensing platform based on mesoporous silica thin film for the detection of prostate specific antigen. Sens. Actuators $B$ Chem. 2018, 255, 309-315. [CrossRef]

24. Llopis-Lorente, A.; Lozano-Torres, B.; Bernardos, A.; Martínez-Máñez, R.; Sancenón, F. Mesoporous silica materials for controlled delivery based on enzymes. J. Mater. Chem. B 2017, 5, 3069-3083. [CrossRef] [PubMed]

25. Pla, L.; Xifre-Perez, E.; Ribes, À.; Aznar, E.; Marcos, M.D.; Marsal, L.F.; Martínez-Máñez, R.; Sancenón, F. A Mycoplasma Genomic DNA Probe using Gated Nanoporous Anodic Alumina. ChemPlusChem 2017, 82, 337-341. [CrossRef] [PubMed]

26. Ribes, A.; Aznar, E.; Santiago-Felipe, S.; Xifre-Perez, E.; Tormo-Mas, M.Á.; Pemán, J.; Marsal, L.F.; Martínez-Máñez, R. Selective and Sensitive Probe Based in Oligonucleotide-Capped Nanoporous Alumina for the Rapid Screening of Infection Produced by Candida albicans. ACS Sens. 2019, 4, 1291-1298. [CrossRef] [PubMed]

27. Goñi, J.R.; Vaquerizas, R.E.-G.A.S.J.M.; Dopazo, J.; Orozco, M. Exploring the reasons for the large density of triplex-forming oligonucleotide target sequences in the human regulatory regions. BMC Genomic 2006, 7, 1-10. [CrossRef] [PubMed]

28. Frank-Kamenetskii, M.D.; Mirkin, S.M. Triplex DNA structures. Annu. Rev. Biochem. 1995, 64, 65-95. [CrossRef] [PubMed]

29. Goñi, J.R.; De La Cruz, X.; Orozco, M. Triplex-forming oligonucleotide target sequences in the human genome. Nucleic Acids Res. 2004, 32, 354-360. [CrossRef] 
30. Aviñó, A.; Frieden, M.; Morales, J.C.; García de la Torre, B.; Güimil García, R.; Azorín, F.; Gelpí, J.L.; Orozco, M.; González, C.; Eritja, R. Properties of triple helices formed by parallel-stranded hairpins containing 8-aminopurines. Nucleic Acids Res. 2002, 30, 2609-2619. [CrossRef]

31. Nadal, A.; Eritja, R.; Esteve, T.; Pla, M. "Parallel" and "Antiparallel Tail-Clamps" Increase the Efficiency of Triplex Formation with Structured DNA and RNA Targets. ChemBioChem 2005, 6, 1034-1042. [CrossRef]

32. Carrascosa, L.G.; Gómez-Montes, S.; Aviñó, A.; Nadal, A.; Pla, M.; Eritja, R.; Lechuga, L.M. Sensitive and label-free biosensing of RNA with predicted secondary structures by a triplex affinity capture method. Nucleic Acids Res. 2012, 40, e56. [CrossRef] [PubMed]

33. Aviñó, A.; Huertas, C.S.; Lechuga, L.M.; Eritja, R. Sensitive and label-free detection of miRNA-145 by triplex formation. Anal. Bioanal. Chem. 2016, 408, 885-893. [CrossRef] [PubMed]

34. Wei, S.; Chen, G.; Jia, X.; Mao, X.; Chen, T.; Mao, D.; Zhang, W.; Xiong, W. Exponential amplification reaction and triplex DNA mediated aggregation of gold nanoparticles for sensitive colorimetric detection of microRNA. Anal. Chim. Acta 2020, 1095, 179-184. [CrossRef] [PubMed]

35. Ribes, À.; Santiago-Felipe, S.; Aviñó, A.; Candela-Noguera, V.; Eritja, R.; Sancenón, F.; Martínez-Máñez, R.; Aznar, E. Design of oligonucleotide-capped mesoporous silica nanoparticles for the detection of miRNA-145 by duplex and triplex formation. Sens. Actuators B Chem. 2018, 277, 598-603. [CrossRef]

36. Pascual, L.; Baroja, I.; Aznar, E.; Sancenón, F.; Marcos, M.D.; Murguia, J.R.; Amoros, P.; Rurack, K.; Martínez-Máñez, R. Oligonucleotide-capped mesoporous silica nanoparticles as DNA-responsive dye delivery systems for genomic DNA detection. Chem. Commun. 2015, 51, 1414-1416. [CrossRef]

37. Oroval, M.; Coll, C.; Bernardos, A.; Marcos, M.D.; Martínez-Máñez, R.; Shchukin, D.G.; Sancenón, F. Selective Fluorogenic Sensing of As(III) Using Aptamer-Capped Nanomaterials. ACS Appl. Mater. Interfaces 2017, 9, 11332-11336. [CrossRef]

38. Vojkuvka, L.; Marsal, L.F.; Ferré-Borrull, J.; Formentin, P.; Pallares, J. Self-ordered porous alumina membranes with large lattice constant fabricated by hard anodization. Superlattices Microstruct. 2008, 44, 577-582. [CrossRef]

39. Matsumura, Y.; Tsuchido, Y.; Yamamoto, M.; Nakano, S.; Nagao, M. Development of a fully automated PCR assay for the detection of Pneumocystis jirovecii using the GENECUBE system. Med. Mycol. J. 2019, 57, 841-847. [CrossRef]

40. Yang, S.-L.; Wen, Y.-H.; Wu, Y.-S.; Wang, M.-C.; Chang, P.-Y.; Yang, S.; Lu, J.-J. Diagnosis of Pneumocystis pneumonia by real-time PCR in patients with various underlying diseases. J. Microbiol. Immunol. Infect. 2019, 5, 785-790. [CrossRef]

41. Moodley, B.; Tempia, S.; Frean, J.A. Comparison of quantitative real-time PCR and direct immunofluorescence for the detection of Pneumocystis jirovecii. PLoS ONE 2017, 12, e0180589. [CrossRef]

42. Alanio, A.; Desoubeaux, G.; Sarfati, C.; Hamane, S.; Bergeron, A.; Azoulay, É.; Molina, J.; DeRouin, F.; Menotti, J. Real-time PCR assay-based strategy for differentiation between active Pneumocystis jirovecii pneumonia and colonization in immunocompromised patients. Clin. Microbiol. Infect. 2011, 17, 1531-1537. [CrossRef] [PubMed]

43. Marimuthu, S. Development of a Real-time PCR assay for Pneumocystis jirovecii on the Luminex ARIES ${ }^{\circledR}$ Platform. Univ. Louisev. J. Respir. Infect. 2019, 3, 5. [CrossRef]

44. Cissé, O.H.; Almeida, J.M.G.C.F.; Fonseca, Á.; Kumar, A.A.; Salojärvi, J.; Overmyer, K.; Hauser, P.M.; Pagni, M. Genome Sequencing of the Plant Pathogen Taphrina deformans, the Causal Agent of Peach Leaf Curl. MBio 2013, 4, e00055-13. [CrossRef]

45. Rojas, P.; Friaza, V.; García, E.; De La Horra, C.; Vargas, S.L.; Calderón, E.J.; Pavón, A. Early Acquisition of Pneumocystis jirovecii Colonization and Potential Association with Respiratory Distress Syndrome in Preterm Newborn Infants. Clin. Infect. Dis. 2017, 65, 976-981. [CrossRef] [PubMed]

46. Kidd, S.E.; Chen, S.C.-A.; Meyer, W.; Halliday, C.L. A New Age in Molecular Diagnostics for Invasive Fungal Disease: Are We Ready? Front. Microbiol. 2020, 10, 2903. [CrossRef]

Publisher's Note: MDPI stays neutral with regard to jurisdictional claims in published maps and institutional affiliations. 